\title{
SISTEMA DE SINCRONISMO ENTRE A COLHEDORA DE CANA-DE-AÇÚCAR E O VEÍCULO DE TRANSBORDO ${ }^{1}$
}

\section{PAUlO S. G. MAGALHÃES ${ }^{2}$, RODRIGO F. G. BALDO ${ }^{3}$, DOMINGOS G. P. CERRI ${ }^{4}$}

RESUMO: Um dos problemas encontrados na colheita mecanizada da cana-de-açúcar é a falta de sincronismo entre a colhedora e o transbordo, ocasionando perdas tanto de material como de capacidade operacional. A presente pesquisa teve como objetivo desenvolver um sistema capaz de auxiliar no sincronismo entre a colhedora e o veículo de transbordo por meio de comunicação sem fio. Dois sensores de ultra-som acoplados ao elevador e um microprocessador gerenciam tais informações, gerando correta sincronia entre as máquinas. O sistema foi testado em laboratório e em campo, cumprindo corretamente a função de manter as máquinas em sincronia, indicando e alertando aos operadores as suas posições relativas. O sistema desenvolvido reduziu as perdas de rebolo em cerca de $60 \mathrm{~kg} \mathrm{ha}^{-1}$, comparado com a colheita realizada com o sistema desligado.

PALAVRAS-CHAVE: ultra-som, otimização, controle.

\section{SYSTEM OF SYNCHRONISM BETWEEN SUGAR CANE HARVEST MACHINE AND INFIELD WAGON}

\begin{abstract}
One of the problems found in mechanical harvest of sugar cane is the lack of synchronism between the harvest machine and the infield wagon, causing crop losses as well as operational capacity. The objective of the present research was to design a system capable of helping to synchronize the sugar cane harvest machine with the wagon. The communication between tractor and harvest machine is wireless. Two ultrasound sensors coupled to the elevator and a microprocessor manage such information, generating a correct synchronization among the machines. The system was tested in laboratory and on field performing its function adequately, maintaining the two machines in synchronization, indicating and alerting the operators their relative positions. The developed system reduced the sugar cane lost in $60 \mathrm{~kg} \mathrm{ha}^{-1}$ comparing to the harvest with the system turned off.
\end{abstract}

KEYWORDS: ultrasound, wagon, harvest machine.

\section{INTRODUÇÃO}

A produção brasileira de cana-de-açúcar, para a safra 2006/2007, foi de 474,8 milhões de toneladas, de acordo com a Companhia Nacional de Abastecimento (CONAB, 2007), 10\% superior à da safra anterior, incremento esse associado à expansão de 205 mil hectares na área, o que correspondente a 5,5\% de aumento na comparação com o período anterior. Os investimentos em tecnologia e em novas usinas, estimulados principalmente pelos bons preços dos produtos no mercado, são responsáveis diretos pelo avanço conseguido (ANUÁRIO BRASILEIRO DA CANADE-AÇÚCAR, 2005).

Dentro do ciclo operacional gerado pela cana-de-açúcar, a etapa da colheita pode ser considerada como uma das mais importantes, pois dela depende a qualidade do produto entregue às usinas. Atualmente, $30 \%$ da área colhida de cana-de-açúcar utiliza o processo mecanizado de colheita, com ou sem queima prévia para limpeza do canavial. As áreas que utilizam a colheita mecanizada estão localizadas principalmente em locais com topografia adequada e/ou apresentam problemas relacionados à escassez de mão-de-obra.

\footnotetext{
${ }^{1}$ Extraído da Dissertação de Mestrado do segundo autor.

${ }^{2}$ Professor Titular, FEAGRI/UNICAMP, Campinas - SP, Fone: (0XX19) 3521.1053, graziano@agr.unicamp.br

${ }^{3}$ Eng $^{\mathrm{O}}$ Eletricista, Mestre em Engenharia Agrícola, Doutorando, FEAGRI/UNICAMP, Campinas - SP.

${ }^{4}$ Eng ${ }^{0}$ Agrônomo, Doutor em Engenharia Agrícola, Pesquisador Colaborador, FEAGRI/UNICAMP, Campinas - SP.

Recebido pelo Conselho Editorial em: 11-9-2007

Aprovado pelo Conselho Editorial em: 4-3-2008
} 
Com o crescimento da demanda de cana-de-açúcar e a competitividade de preço dos produtos, o setor agrícola está buscando maior eficiência e melhor tecnologia para o campo, investindo, assim, em equipamentos que proporcionam menor perda de matéria-prima, redução da contaminação de cana-de-açúcar com impurezas minerais e, conseqüentemente, maior lucratividade.

De acordo com BRAUNBECK \& MAGALHÃES (2004), os processos convencionais de colheita manual ou mecânica, com ou sem queima prévia, visam apenas ao aproveitamento dos colmos e estão constituídos de seqüência de operações simples que incluem o corte da base, do ponteiro e a picagem ou o empilhamento dos colmos. Vários trabalhos científicos já foram apresentados com o intuito de avaliar o desempenho dessas colhedoras, tanto em relação ao seu desempenho operacional (DICK, 1986; DICK \& HILTON, 1992; KROES \& HARRIS, 1999; RIPOLI et al., 2001; SALVI et al., 2007) quanto em relação às perdas de matéria-prima presentes na colhedora (RIPOLI et al., 1996; NEVES et al., 2003; NEVES et al., 2006), porém nenhum desses trabalhos reporta ou quantifica um tipo de perda que ocorre durante a colheita, devido à falta de sincronismo entre a colhedora e o veículo de carregamento do material colhido.

Para reduzir essas perdas e melhorar a eficiência das colhedoras, alguns trabalhos de pesquisa têm sido conduzidos com o intuito de instrumentar e de monitorar as colhedoras de cana-de-açúcar. NEVES et al. (2004) instalaram em uma colhedora CASE um monitor de perdas de cana-de-açúcar desenvolvido especialmente para esse fim. Esse monitor era composto de sensor piezelétrico de impacto instalado na carenagem ("capuz") de eliminação de matéria estranha do extrator primário da colhedora, de mostrador digital, que apresenta a contagem de impactos captados pelo sensor. Os resultados mostraram que a eficiência de limpeza do extrator primário, as perdas de cana-de-açúcar, em geral, e a velocidade do ventilador estão diretamente relacionados.

A preocupação com a redução das perdas e com a melhora da eficiência das colhedoras também é compartilhada pelos fabricantes. A Cameco instalou em suas máquinas um dispositivo para o controle automático de altura de corte basal. Esse dispositivo foi avaliado por SALVI et al. (2007), analisando a altura de corte e as impurezas na matéria-prima para uma colhedora de canade-açúcar picada, operando com e sem o dispositivo, e com dois operadores distintos. $\mathrm{O}$ uso do dispositivo auxiliou na manutenção da altura de corte, principalmente para operadores com menos habilidade/experiência. Essa preocupação com a instrumentação e o monitoramento da colhedora também está presente nos gerentes agrícolas das usinas, como pode ser observado no trabalho apresentado por MENEGATTI et al. (2006). Os autores descrevem o sistema implementado na Usina Cerradinho para monitoramento e controle de veículos, transbordo e rendimento das carregadoras de cana-de-açúcar utilizadas na colheita manual. Para a implementação do sistema, foi necessária a instalação de diversos sensores e instrumentos em todos os equipamentos utilizados durante a colheita e o transporte da cana-de-açúcar até o hilo da usina.

MAGALHÃES \& CERRI (2007) desenvolveram um monitor de produtividade de cana-deaçúcar para colhedoras autopropelidas. O sistema é capaz de mensurar o fluxo de rebolos que passam pela esteira antes de serem lançados ao veículo de transbordo. Para determinar o peso da matéria-prima colhida, células de carga foram instaladas no elevador da colhedora. Esses dados, juntamente com as informações obtidas por um GPS instalado na colhedora, permitem a elaboração de um mapa digital que representa a superfície de produção para a área colhida.

Como se pode perceber, as perdas decorrentes da colheita mecanizada de cana-de-açúcar são expressivas e existe preocupação com sua redução, tanto por parte dos fabricantes como dos usuários.

Com o intuito de reduzir as perdas decorrentes da colheita mecanizada e contribuir com a melhora da eficiência operacional do conjunto, esta pesquisa visou a desenvolver um sistema de alerta de falta de sincronismo entre a colhedora e o transbordo por meio de comunicação sem fio, denominado como STC (Sincronismo Transbordo Colhedora). 


\section{MATERIAL E MÉTODOS}

Para atingir tal objetivo, este trabalho consistiu na adaptação de sensores de ultra-som na colhedora, no desenvolvimento do programa gerenciador, na confecção de interface homemmáquina para a interpretação lógica dos dados provenientes dos sensores e no desenvolvimento de sistema de comunicação sem fio entre as máquinas.

As perdas decorrentes da falta de sincronismo podem ser classificadas de duas maneiras. A primeira está relacionada com a quantidade de rebolos de cana-de-açúcar lançados ao solo quando o elevador da colhedora não está posicionado dentro dos limites do transbordo (Figura 1) ou, ainda, quando há transição de uma caçamba para outra. Já a segunda refere-se à perda operacional da colheita, pois, ao perder o sincronismo, a colheita tem de ser paralisada para que as duas máquinas se alinhem novamente.

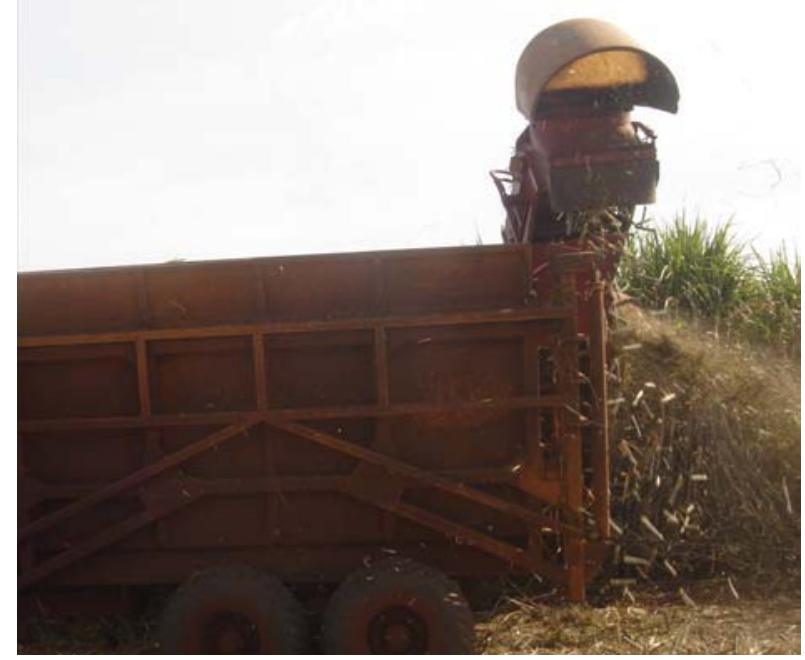

(a)

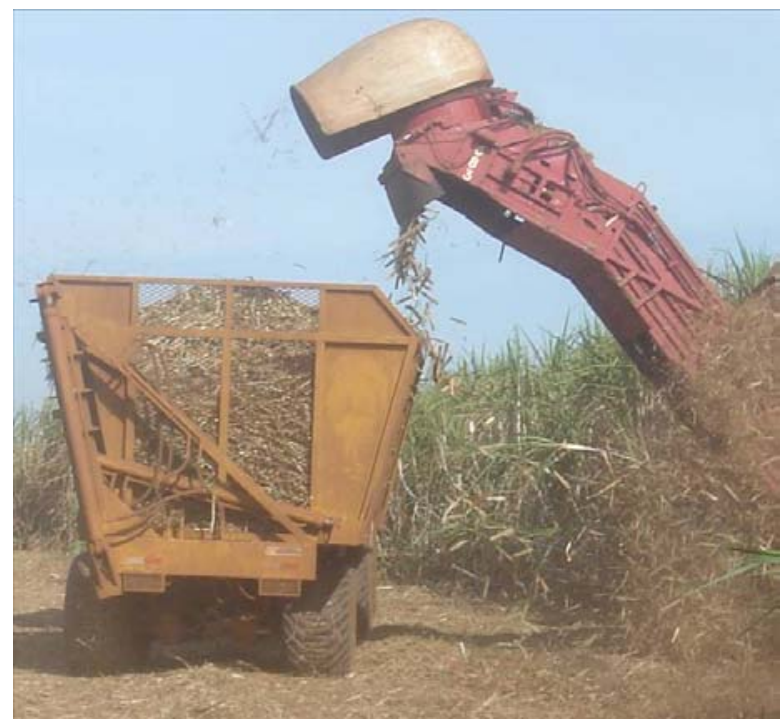

(b)

FIGURA 1. (a) Perda por falta de sincronismo. (b) Perda por falta de paralelismo. a) Material lost for lack of synchronization. b) Material lost for lack of parallelism.

Atualmente, esse alinhamento é realizado visualmente pelo operador da colhedora e do transbordo, por isso demanda tempo e causa perda de eficiência operacional.

Para o desenvolvimento do dispositivo de sincronismo entre a colhedora de cana-de-açúcar e o transbordo, foram utilizados: a) dois sensores de ultra-som da marca Parallax para detectar a presença do transbordo; b) um transmissor e um receptor de radiofreqüência, operando na faixa de $433 \mathrm{MHz}$, para a transmissão do sinal entre as duas máquinas, com alcance máximo de $50 \mathrm{~m}$; c) dois microcontroladores PIC16F628, um localizado no transbordo e o outro na colhedora - esse último responsável tanto pelo controle dos sensores, como pelo envio das informações de posicionamento relativo à interface da colhedora e ao segundo microcontrolador localizado no transbordo, sendo esse último responsável somente pela recepção das informações e pelo envio delas à interface do operador do transbordo.

O sensor de ultra-som utilizado é composto de dois dispositivos (um emissor e outro receptor) e baseia-se no tempo de propagação da onda emitida por um impulso de nível lógico 1, com a duração de $5 \mu \mathrm{s}$. Após receber esse impulso de disparo do microcontrolador, o sensor envia um sinal acústico ultra-sônico e manda de volta ao microcontrolador um nível lógico 1, ficando em seguida à espera do retorno do sinal acústico, denominado eco. Assim que o eco é recebido, o nível lógico 1 passa novamente a 0 . O microcontrolador foi programado para medir o tempo que o eco demorou a ser detectado e, dessa forma, calculou a distância a que se encontra o obstáculo que provocou o eco. Dois desses sensores foram instalados na extremidade do elevador da colhedora, sendo capazes de detectar a presença de qualquer objeto localizado sob a esteira. As informações de 
posicionamento relativo geradas pelos sensores e processadas pelos microcontroladores são visualizadas nas interfaces homem-máquina. Essas interfaces estão localizadas na cabine da colhedora e na cabine do trator do transbordo. O seu funcionamento dá-se por meio de LED e alerta sonoro, como mostrado na Figura 2.

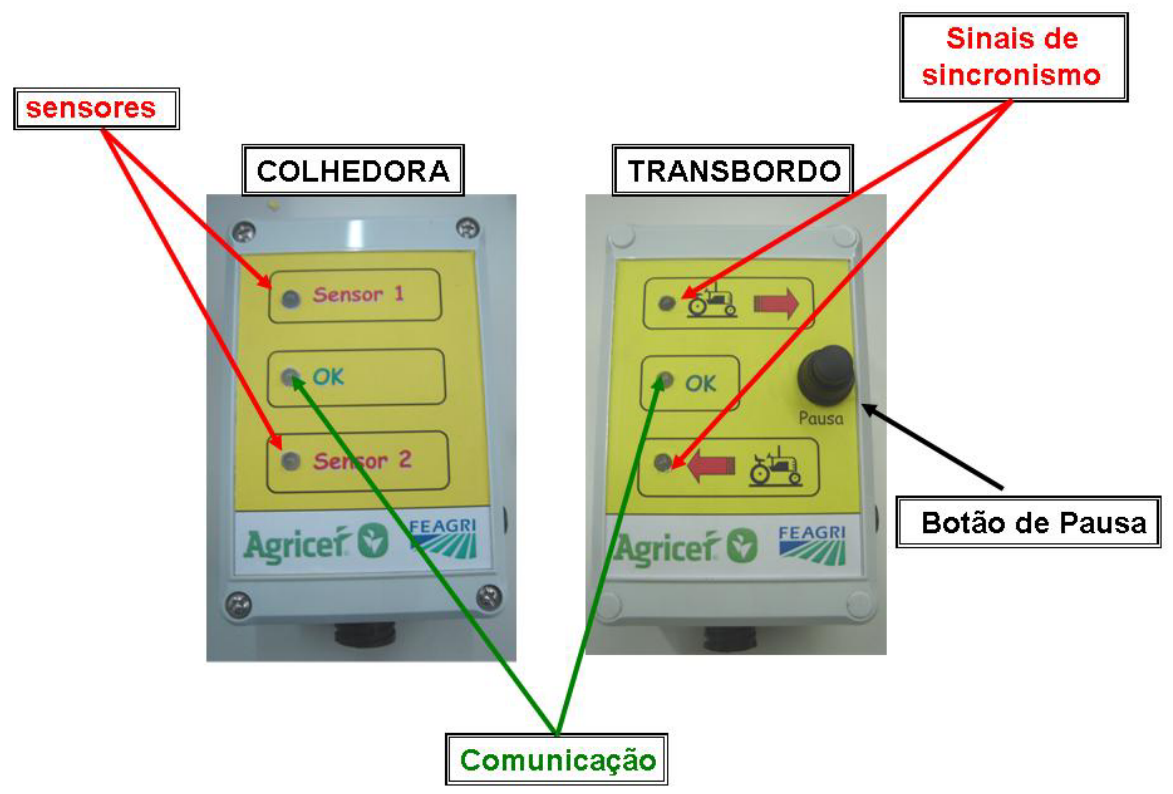

FIGURA 2. Interface da colhedora e do transbordo. Interface harvester machine and infield wagon.

Os sensores de ultra-som foram instalados na extremidade do elevador da colhedora com inclinação de $5^{\circ}$ em relação ao plano horizontal para que o sistema identifique a saída do transbordo antes que ela ocorra (FIGURA 3). Essa inclinação foi estabelecida a partir de ensaios de laboratório, de acordo com o ângulo de leitura do sensor, seu posicionamento na colhedora e a localização do veículo de transbordo.

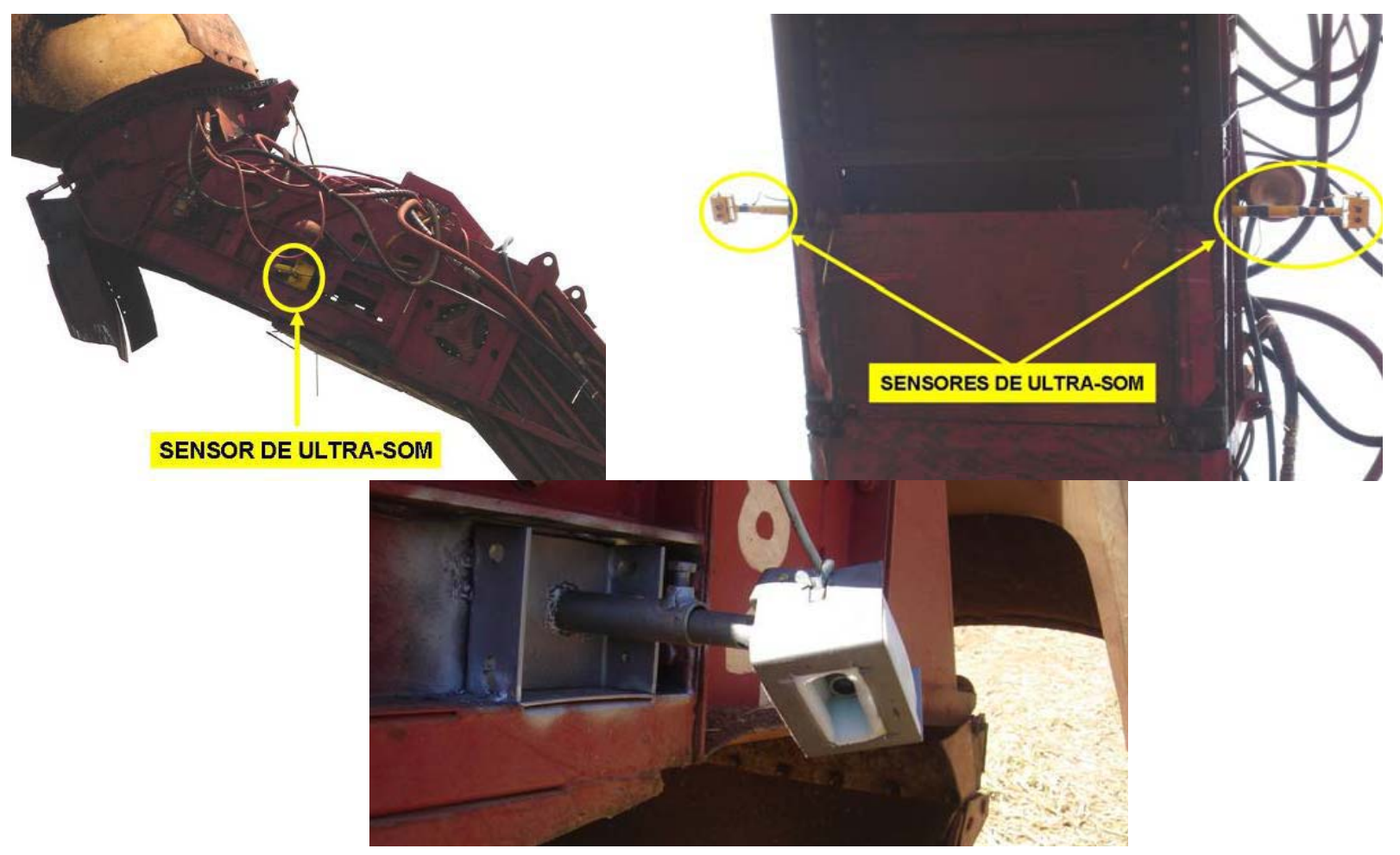

FIGURA 3. Localização dos sensores na colhedora. Sensor localization in the harvest machine. 
Para o gerenciamento correto das decisões a serem tomadas sobre a posição de uma máquina em relação à outra, foram escritos dois programas computacionais em Assembler, um para a colhedora e outro para o transbordo. O primeiro programa gravado no microcontrolador localizado no módulo colhedora monitora os sensores de ultra-som, verificando, dessa forma, se o elevador da colhedora está posicionado acima do transbordo. Caso não esteja, o programa verifica qual dos sensores está fora de posicionamento e envia pelo transmissor RF qual decisão (acelerar ou reduzir a velocidade) o operador do conjunto trator-transbordo deve tomar. Essa informação é visualizada pelo operador por meio da interface homem-máquina. $\mathrm{O}$ monitoramento dos sensores dá-se por meio de comparação. Toda vez que existe alteração elevada da leitura de distância realizada pelo sonar, o programa interpreta como posicionamento indevido do veículo de transbordo, informando ao operador a reação a ser adotada.

O segundo programa, gravado no microcontrolador localizado no módulo transbordo, recebe via radiofreqüência as informações de posicionamento relativo oriundas do módulo colhedora e informa ao operador a situação do conjunto e que procedimento ele deve adotar.

Para tornar a comunicação entre as máquinas mais segura, o módulo colhedora envia três valores $0 \times 55 \mathrm{H}$ em hexadecimal antes de enviar um código. $\mathrm{O}$ valor $0 \times 55 \mathrm{H}$ é uma forma de onda quadrada e isso ajuda a sincronizar o transmissor com o receptor. Após enviar essa onda quadrada, o módulo manda os dados desejados que podem ser: acelerar, reduzir ou aviso sonoro. $\mathrm{O}$ módulo transbordo recebe esses dados e executa a função desejada.

O experimento foi conduzido na Usina São Luiz, localizada no município de Pirassununga SP. As coordenadas geográficas são: $21^{\circ} 57^{\prime} \mathrm{S}$ e $47^{\circ} 22^{\prime} \mathrm{W}$, elipsóide WGS84. A variedade de canade-açúcar plantada em 2003, na área de estudo, foi a SP80-1816. Na safra de 2006, a produtividade média do talhão foi de $79,8 \mathrm{Mg} \mathrm{ha}^{-1}$. Para a realização dos testes, separou-se área $12,2 \mathrm{ha}$, de topografia plana, com $450 \mathrm{~m}$ de largura por $270 \mathrm{~m}$ de comprimento, com o total de 300 fileiras de cana-de-açúcar espaçadas de 1,5 m cada. A área foi previamente queimada para facilitar a coleta dos rebolos de cana-de-açúcar que foram perdidos (FIGURA 4).
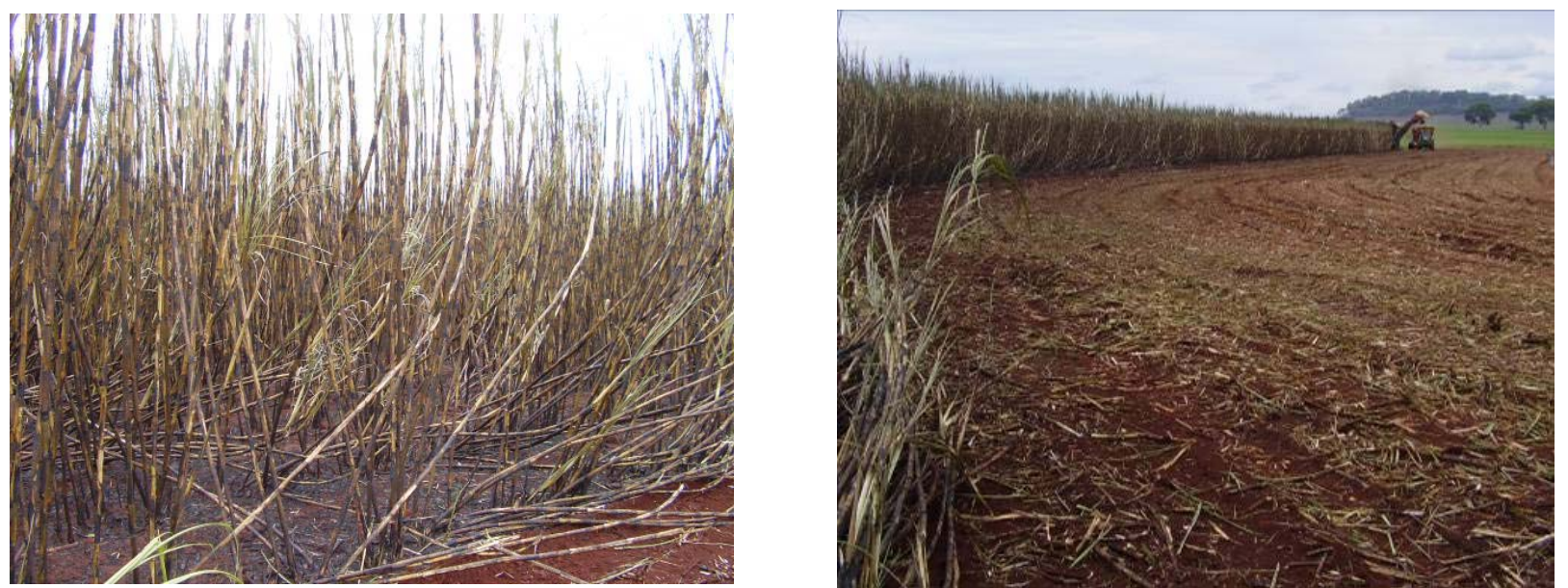

FIGURA 4. Aspectos gerais da área destinada aos testes. General view of the field where testes were conducted.

A área foi subdividida em 30 parcelas contendo 10 fileiras (FIGURA 5). De forma alternada, foram selecionadas parcelas nas quais a máquina trabalhou com o STC (Sincronismo Transbordo Colhedora) ligado e outras em que o STC foi desligado. Ao término da colheita de cada parcela, eram descartadas as duas primeiras e as duas últimas fileiras, chamadas de bordadura, e sorteava-se, entre as fileiras restantes ( 3 a 7 ), duas para a análise de perdas. 


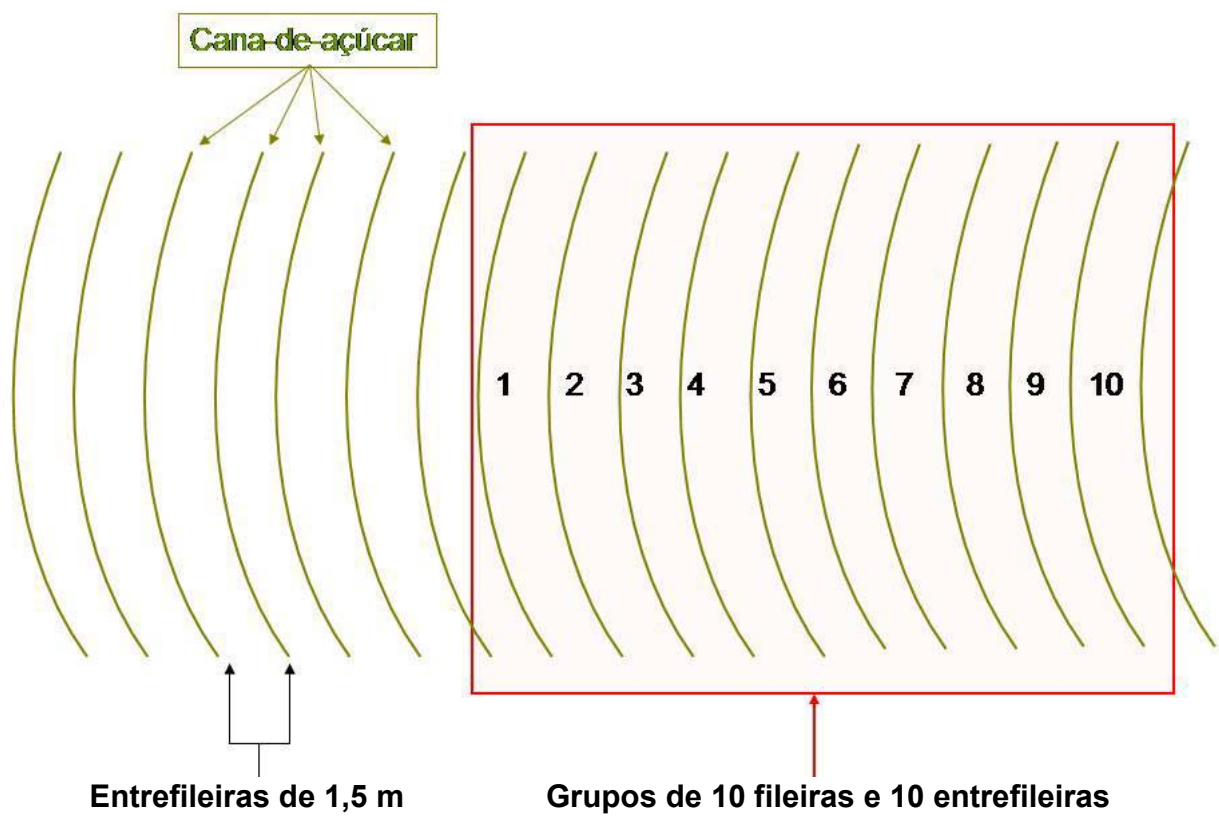

FIGURA 5. Esquema da área de ensaio e seleção do grupo de fileiras utilizadas na avaliação do sistema. Schematic view of the test field and selection of row group used in the evaluation system.

As perdas visíveis de cana-de-açúcar provenientes da colheita mecânica (Figura 6) podem ser classificadas, segundo NEVES et al. (2003), como:

Tocos - fração do colmo cortada acima da superfície do solo, presa às raízes não-arrancadas, com comprimento menor ou igual a $0,2 \mathrm{~m}$; comprimentos maiores são considerados pedaços.

Cana inteira - fração de cana-de-açúcar com tamanho igual ou superior a $2 / 3$ do comprimento normal estimado dos colmos do local; esse colmo pode ou não estar preso ao solo pelas raízes.

Cana-ponta - fração de colmo deixada no solo e agregada ao ponteiro. A retirada de canaponta foi efetuada quebrando-se manualmente o colmo, no ponto de menor resistência.

Rebolos - fração do colmo com o corte característico do facão picador ou do corte de base, em ambas as extremidades.

Lascas - fragmentos de cana-de-açúcar dilacerados.

Pedaços - todas as variações visíveis de colmos sem as características que definam tocos, colmos inteiros, rebolos, lascas e ponta de cana-de-açúcar e que, portanto, não se encaixam em nenhuma das definições anteriormente citadas.

Dessas, apenas as perdas de rebolos deixados no campo após a colheita são de interesse deste trabalho, sendo a percentagem de perdas de rebolo (Pr) determinada pela relação entre a massa de material coletado no campo $(\mathrm{Mr})\left(\mathrm{Mg} \mathrm{ha}^{-1}\right)$ e a produtividade média do talhão $\left(\mathrm{M}_{\mathrm{T}}\right)\left(\mathrm{Mg} \mathrm{ha}^{-1}\right)$, calculado de acordo com a eq.(1):

$$
\operatorname{Pr}=\left(\frac{\mathrm{M}_{\mathrm{r}}}{\mathrm{M}_{\mathrm{T}}}\right) 100
$$

Todos os cálculos foram efetuados com base em massa seca, de modo a permitir a comparação entre resultados.

Os rebolos encontrados no solo foram recolhidos e, ao final de cada linha, pesados, utilizando balança marca Urano, com divisão de $5 \mathrm{~g}$. Esse procedimento foi repetido 15 vezes para cada sistema.

Os resultados coletados foram analisados por meio da análise de variância (ANOVA). 


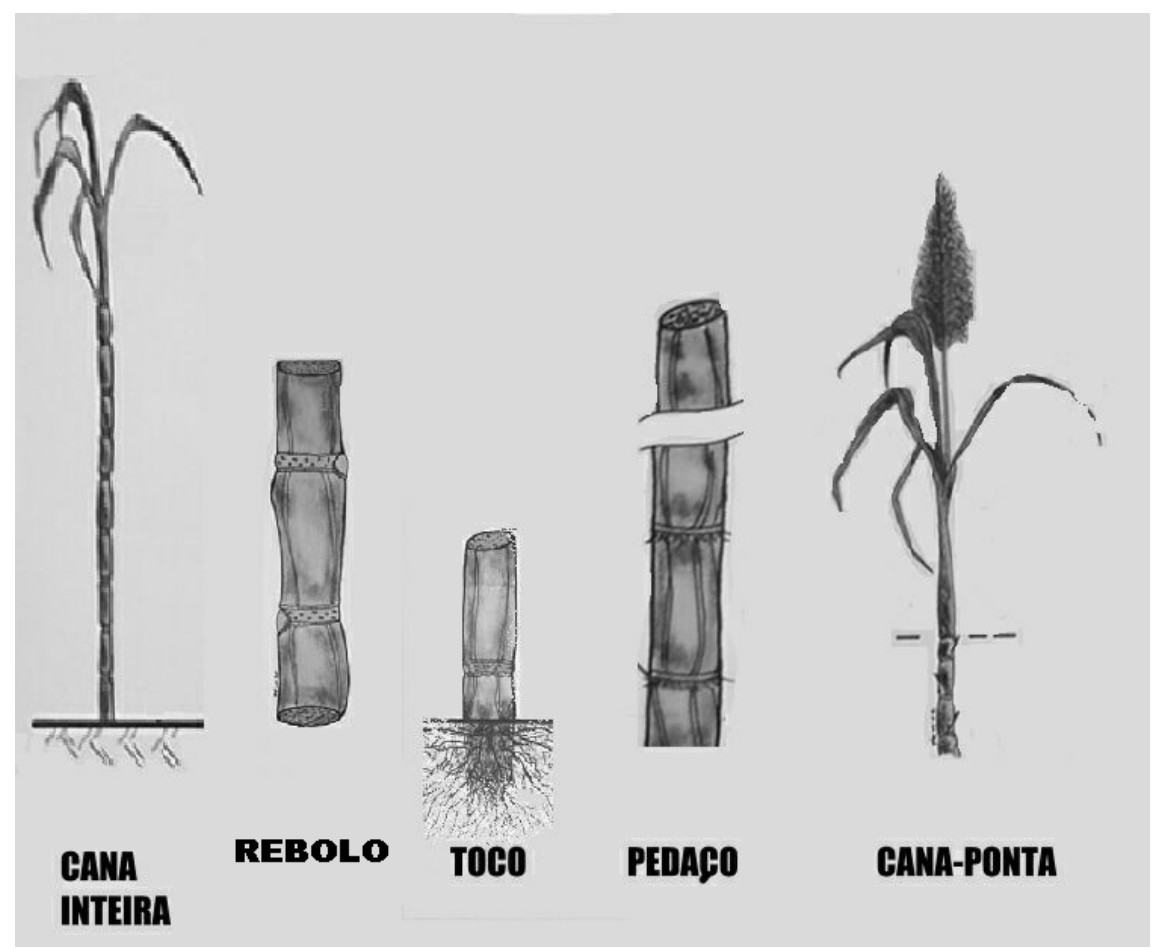

FIGURA 6. Classificação das perdas visíveis de cana-de-açúcar. Classification of visible sugarcane losses.

\section{RESULTADOS E DISCUSSÃO}

Nos testes de sensibilidade, os sensores identificaram corretamente a presença do transbordo e também, de forma consistente (100\% dos casos), sinalizaram quando os mesmos saíam da sua área de alcance. Em relação aos testes de transmissão de sinal, observou-se que todos os sinais enviados pela colhedora (100\%) foram captados corretamente pelo transbordo no raio de $10 \mathrm{~m}$. Cada sistema (ligado e desligado) foi avaliado em uma área de 1,21 ha.

Obteve-se que o total de perdas de rebolos da colheita com o sistema desligado foi de $769,84 \mathrm{~kg} \mathrm{ha}^{-1}$, o que significa perda de $0,96 \%$ para esse talhão. Esses valores estão condizentes com os valores obtidos por NEVES et al. (2003); nesse levantamento, os autores encontraram valores de perdas visíveis totais de matéria-prima no campo após a colheita, entre 10 e $17 \%$, e de rebolos, em especial, entre 0,7 e $0,9 \%$.

Para o sistema ligado, a perda total de rebolos foi de $707,02 \mathrm{~kg} \mathrm{ha}^{-1}(0,86 \%)$, portanto a diferença foi de $62,82 \mathrm{~kg} \mathrm{ha}^{-1}$ ou $8,16 \%$ de redução nas perdas de rebolos. Na Tabela 1, apresenta-se a análise de variância para a variável testada.

TABELA 1. Análise de variância para a variável perda de rebolos com e sem o STC operando. Valores em kg. Analysis for the billets losses with STC on and off, values are in kg.

\begin{tabular}{|c|c|c|c|c|c|}
\hline Fonte & $\begin{array}{c}\text { Soma de } \\
\text { Quadrados }\end{array}$ & Graus de Liberdade & Quadrado Médio & $\mathrm{F}_{\text {calculado }}$ & $\mathrm{P}_{\text {valor }}$ \\
\hline Entre grupos & 343,408 & 1 & 343,408 & 9,84 & 0,0040 \\
\hline Dentro dos grupos & 977,050 & 28 & 34,894 & & \\
\hline Total & $1.320,459$ & 29 & & & \\
\hline
\end{tabular}

A análise de variância (ANOVA) resultou um Pvalor igual a 0,0040 $(<0,05)$, podendo-se concluir que existe diferença significativa entre as médias de um sistema para outro, a 95\% de confiança. Na Figura 7, apresenta-se esse resultado com o intervalo de LSD (Least Significant Difference) com 95\% de confiabilidade para perda nos dois sistemas. 


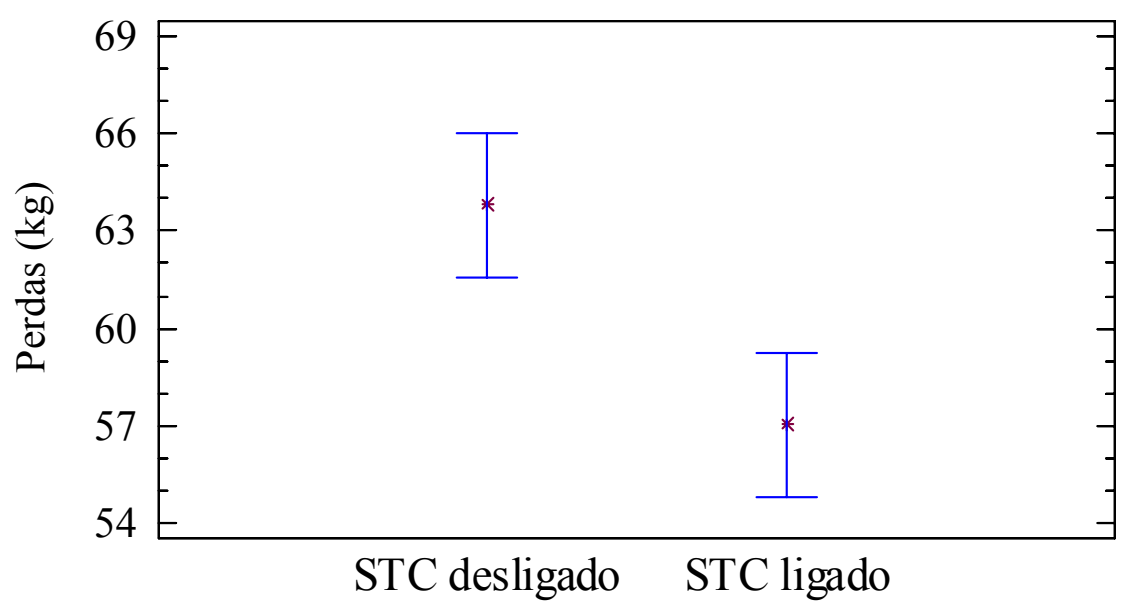

FIGURA 7. Média e intervalo de confiança com $95 \%$ de confiabilidade para a perda de rebolos $(\mathrm{kg})$, utilizando o STC ligado e desligado. Average and confidence interval with 95\% of LSD, for billets losses (kg), using STC on and off.

Considerando que a máquina colhe por dia $600 \mathrm{Mg} \mathrm{ha}^{-1} \mathrm{em}$ um talhão com produtividade média de $80 \mathrm{Mg} \mathrm{ha}^{-1}$, a capacidade operacional da máquina é de 7,5 ha por dia. Com a economia do sistema de $62,82 \mathrm{~kg} \mathrm{ha}^{-1}$, a redução das perdas seria de $471 \mathrm{~kg}$ por dia por máquina. Como a duração média da safra é de aproximadamente 180 dias, portanto a redução total de perdas de rebolos ao longo da safra seria de aproximadamente $85 \mathrm{Mg}$ por máquina, trabalhando com o sistema proposto.

Essa redução não foi maior devido ao fato de que as perdas provenientes do transbordo não são só referentes ao sincronismo das máquinas. Pôde-se observar, nos testes realizados em campo, que uma parte das perdas é causada pela falta de sincronismo, porém a grande maioria é proveniente do excesso de carga no transbordo e do acúmulo de rebolos no bojo, onde é realizado o armazenamento da cana-de-açúcar picada e a alimentação da esteira.

Em relação aos benefícios aos operadores dos equipamentos, não foi possível avaliar quantitativamente, porém observou-se que o sistema reduz o número de tarefas dos operadores na colhedora, além de melhorar a ergonomia para o operador, contribuindo para a redução da sua carga de estresse, principalmente no período noturno, quando a visibilidade é reduzida.

\section{CONCLUSÕES}

Por meio dos resultados, pode-se concluir que o sistema é eficiente para alertar a presença ou não do transbordo sob a esteira da colhedora de cana-de-açúcar, diminuindo a perda de material e melhorando a eficiência de campo do conjunto. Em relação às perdas, o sistema reduziu-as em $62,82 \mathrm{~kg} \mathrm{ha}^{-1}$ ou $8,2 \%$ comparado com a colheita realizada com o sistema desligado.

\section{AGRADECIMENTOS}

À FAPESP e ao CNPq, pelo apoio financeiro; à CAPES, pela concessão de bolsa ao segundo autor, e à Usina São Luiz, Pirassununga - SP, pela disponibilidade da área e pela colaboração de seus funcionários no projeto.

\section{REFERÊNCIAS}

ANUÁRIO BRASILEIRO DA CANA-DE-AÇÚCAR. Cultura de impacto. Santa Cruz do Sul: Gazeta Santa Cruz, 2005. p.12-13.

BRAUNBECK, O.A.; MAGALHÃES, P.S.G. Colheita sustentável com aproveitamento integral da cana. Visão Agrícola, Piracicaba, v.1, n.1, p.72-9, 2004. 
CONAB. COMPANHIA NACIONAL DE ABASTECIMENTO. Acompanhamento da Safra Brasileira. Cana-de-açúcar, primeiro levantamento, safra 2007/2008. Brasília, 2007. 12 p.

DICK, R.G. Potential losses higher when harvesting green. BSES Bulletin, Austrália, n.15, p.18-10, Jul. 1986.

DICK, R.G.; HILTON J.D. Sensor and control technology in sugarcane harvesters. In: AUSTRALIAN SOCIETY OF SUGAR CANE TECHNOLOGISTS CONFERENCE, 14., 1992, Mackay. Proceedings... Brisbane: Watson Ferguson, 1992, p.179-86.

KROES, S.; HARRIS, H.D. The optimum harvester forward speed. Zuckerindustrie, Berlin, v.124, n.2, p.126-30, 1999.

MAGALHÃES, P.S.G.; CERRI, D.G.P. Yield monitoring of sugar cane. Biosystems Engineering, London, v.96, n.1, p.1-6, 2007.

MENEGATTI, L.A.A.; MOLIN, J.P.; GÓES, L.S.; KORNDORFER, G.H.; SOARES, R.A.B.; LIMA E.A. Benefícios econômicos e agronômicos da adoção da agricultura de precisão em usinas de cana-de-açúcar. In: CONGRESSO BRASILEIRO DE AGRICULTURA DE PRECISÃO, 2006, Piracicaba. Anais... 1 CD-ROM.

NEVES, J.L.M.; MAGALHÃES, P.S.G.; MORAES, E.E.; MARCHI, A.S. Avaliação de perdas invisíveis de cana-de-açúcar nos sistemas da colhedora de cana picada. Engenharia Agrícola, Jaboticabal, v.23, n.3, p.539-46, 2003.

NEVES, J.L.M.; MAGALHÃES, P.S.G.; OTA, W.M. Sistema de monitoramento de perdas visíveis de cana-de-açúcar em colhedora de cana picada. Engenharia Agrícola, Jaboticabal, v.24, n.3, p.76470, 2004.

NEVES, J.L.M.; MAGALHÃES, P.S.G.; MORAES, E.E.; ARAÚJO, F.V.M. Avaliação de perdas invisíveis na colheita mecanizada em dois fluxos de massa de cana-de-açúcar. Engenharia Agrícola, Jaboticabal, v.26, n.3, p.787-94, 2006.

RIPOLI,T. C.; FURLANI NETO, V. L.; NOVA, J. Colheita Mecânica: perdas de matéria-prima em canaviais com e sem queima prévia. STAB, Piracicaba, v.14, n.10, p.19-24, 1996.

RIPOLI, T.C.C; NERY, M.S.; MOLINA, W.F; RIPOLI, M.L.C. Operational and economic performance of green cane chopped harvester, in Brazil, In: INTERNATIONAL ANNUAL MEETING ASAE, Sacramento, 2001. St. Joseph: ASAE, 2001. Paper 011003.

SALVI, J.V.; MATOS, M.A.; MILAN M. Avaliação do desempenho de dispositivo de corte de base de colhedora de cana-de-açúcar. Engenharia Agrícola, Jaboticabal, v.27, n.1, p.201-9, 2007. 